\title{
Modular Organization of the Pontine Nuclei: Dendritic Fields of Identified Pontine Projection Neurons in the Rat Respect the Borders of Cortical Afferent Fields
}

\author{
Cornelius Schwarz and Peter Thier \\ Sektion für Visuelle Sensomotorik, Neurologische Universitätsklinik Tübingen, 72076 Tübingen, Germany
}

\begin{abstract}
Cortical afferents transferring information destined for the cerebellum terminate in the pontine nuclei (PN) in a divergent and patchy fashion. We investigated whether the form of dendritic fields of pontine projection neurons which are postsynaptic to the cortical afferents are related to this patchy pattern. To this end we used a triple combination of (1) retrograde labeling (injection of Fluorogold into the
\end{abstract} brachium pontis), (2) anterograde labeling [injection of Dil into cortical areas A17 and Sml(forelimb)], and (3) subsequent intracellular fills of identified projection neurons (Lucifer yellow) in slightly fixed slices of pontine brainstem. In 64 projection neurons whose somata were located within $160 \mu \mathrm{m}$ of the border defined by cortical afferent fields, most of the dendritic trees were found to respect the border. Strikingly, proximal dendrites which were oriented toward the border often bent in order to avoid the boundary. This observation was supported by a quantitative analysis. It revealed that overlap areas of dendritic fields with the neighboring compartment were significantly smaller than those of hypothetical, radially organized dendritic fields of the same size, indicating that the dendritic fields are indeed confined to single compartments. in a second series of experiments, double injections of the anterograde tracers Dil and DiAsp into adjacent sites within one cortical area (A17 or Sml) were made in order to test if the topology of the cortical map is preserved within individual pontine compartments. This, however, does not seem to be the case, since the terminal fields displayed a complex pattern of overlap and nonoverlap rather than a consistent shift of terminal fields expected in the case of preserved topology. The results of the present study are consistent with the view that pontine modules independently process information from different parts of individual cortical areas. We suggest that this characteristic property of the corticopontine projection system might be the morphological basis of the well established fact that somatotopically continuous sensory maps in the cortex are transformed into maps at

\footnotetext{
Received Aug. 15, 1994: revised Nov. 10, 1994; accepted Nov. 16, 1994.

We thank Martin Möck and Yvonne Schmitz for critically reading one of the last versions of the manuscript. We also thank Jil Wiesner and Thomas Wiehr for helping us with the presentation of the drawings and the photomicrographs. Douglas Tweed helped to improve our English. This work was supported by DFG SFB $307-\mathrm{Al}$

Correspondence should be addressed to Cornelius Schwarz. Sektion tür Visuelle Sensomotorik, Neurologische Universitatsklinik Tübingen, IloppeSeyler Strasse 3, 72076 Tübingen, Germany.

Copyright $\bigcirc 1995$ Society for Neuroscience $0270-6474 / 95 / 153475-15 \$ 05.00 / 0$
}

the level of the cerebellar cortex, showing a fractured somatotopy.

[Key words: pontine nuclei, visual cortex, somatosensory cortex, cerebellum, corticopontine projection, anterograde double tracing, retrograde tracing, dendritic morphology, intracellular filling, fixed slices, modular organization]

The pontine nuclei $(\mathrm{PN})$ provide the cerebellum with the majority of its mossy fibers conveying information from widespread motor and sensory areas of the cerebral cortex. Investigating how the PN distributes and processes cortical information is therefore crucial to understanding cerebellar function. Sensory information in the cortex is mapped topologically. Neighboring sites on the sensory surface are mapped on neighboring locations in the cerebral cortex. In marked contrast, this topological order is no longer present in the recipient structure of the cerebrocerebellar pathway, the granular layer in the cerebellum. For the somatosensory system it has been shown that the granular layer contains a fractured somatosensory map of the body which displays two major characteristics. First, neighboring patches or fragments in the granular layer do not necessarily represent neighboring parts of the body but typically code for quite distant parts of the body. Second, borders between neighboring patches are sharp; there exists no overlap zone responding to both distinct body parts represented in adjacent patches (Joseph et al., 1978; Shambes et al., 1978a,b). Cortical stimulation in combination with recording from the granular layer in the cerebellum has furthermore shown that sites within the map in the somatosensory cortex are specifically connected to corresponding sites within the fractured map in the cerebellum. (Bower et al., 1981). These physiological characteristics impose two major constraints on the organization of the cerebrocerebellar fiber system. First, distant parts of the cortical map must connect to adjacent sites in the cerebellum and, vice versa, neighboring parts in the cortex must connect to distant sites in the cerebellum. Second, signals arriving in different patches in the granular layer have to be kept separated from each other.

It is suggestive that the cerebrocerebellar pathway via the PN contributes to this transformation as it is characterized by a high degree of divergence and compartmentalization and projects to nearly the entire cerebellar cortex (for review see Brodal and Bjaalie, 1992). Corticopontine fibers of a given cortical area are not distributed homogeneously in the PN but rather terminate in numerous nonuniform compartments which are usually referred to as "patches," "columns," or "lamellae" (Brodal, 1978, 1987; Wiesendanger and Wiesendanger, 1982; Mihailoff et al., 

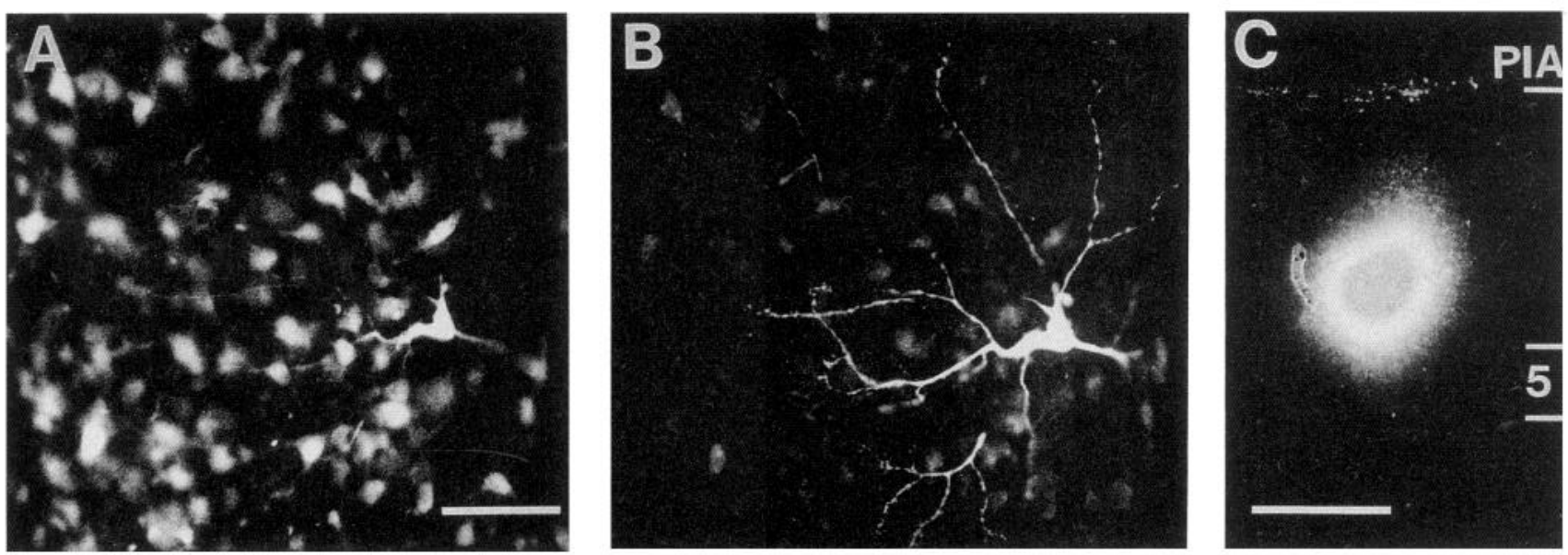

Figure 1. Photomicrographs demonstrating the methods used. A, Retrogradely labeled cells in the PN as seen with illumination for Fluorogold. $B$, One of the cells was filled with Lucifer yellow as seen under illumination for this dye. $C$, Example of a small injection site with DiI in the neocortex. The pial surface and layer 5 , the location of the somata of corticopontine neurons, are signed. Most of the anterogradely transported label in this case was presumably taken up by apical dendrites of corticopontine neurons. Scale bars: $A$ and $B, 50 \mu \mathrm{m} ; C, 500 \mu \mathrm{m}$.

1985; Lee and Mihailoff, 1990). A characteristic of this projection pattern is that each region of the cerebral cortex has its own termination zones in the PN which are segregated from terminal zones of other areas (Brodal, 1968a,b, 1978; Mihailoff et al., $1978,1985)$. In addition to the finding of this striking divergent pattern there are quite deviating views in the literature as to whether there is also convergence from different cortical areas on one and the same pontine compartment. Using cortical stimulation of neighboring cortical areas in combination with recording of orthodromic signals in single pontine neurons, some authors have suggested that such a convergent pattern exists (Rüegg and Wiesendanger, 1975; Rüegg et al., 1977; Potter et al., 1978). However, these results are not entirely convincing, as very high stimulation currents (up to $1.5 \mathrm{~mA}$ ) were used. Stimulation of cortical white matter with such high currents probably activates fibers from widespread parts of the cortex (Yeomans, 1990). Other reports were based on electrical stimulation of more distant cortical areas or used natural sensory stimuli (Oka et al., 1975; Baker et al., 1976; Suzuki et al., 1990). In contrast to the studies mentioned above, these latter ones indicated that convergence of afferents from different cortical areas probably plays a minor role in the corticopontine projection system if it is present at all. This view has been supported by more recent anatomical studies using double anterograde tracing. They revealed that even terminal zones in the PN labeled from adjacent visual areas 17, 18, 19, and PMLS in the cat may be largely separated from each other (Bjaalie, 1989; Bjaalie and Brodal, 1989). Furthermore, the second fiber system within the cerebrocerebellar pathway, the pontocerebellar projection, also seems to be organized in a divergent and patchy manner (Mihailoff et al., 1981b; Mihailoff, 1983; Nikundiwe et al., 1994).

In summary, the prevailing divergence characterizing the cerebropontocerebellar pathway seems to be well suited to distribute cerebral information in the divergent and spatially precise manner which is necessary for the transformation of cerebral into cerebellar maps. However, with regard to the second requirement for this transformation, the segregation of information originating from different parts of cortical areas, it would not only be necessary to avoid overlap between axon terminal fields at the level of the PN; rather, it would be required that dendrites of the recipient pontine neurons actually should integrate information from only one terminal field originating from an individual cortical site. Thus, dendritic fields should avoid crossing borders between neighboring afferent fields. Studies on the dendritic morphology of pontine neurons have indeed yielded observations suggesting that this kind of segregation is present on the level of the pontine nuclei. Besides the fact that dendrites of PN neurons are capable of respecting borders of the nucleus, they also show a striking asymmetry even in the center of the PN (Mihailoff et al., 1981a; C. Schwarz and P. Thier, unpublished observations). Such an asymmetry would be expected if neurons tended to connect selectively to one patch of cortical axon terminals while avoiding input from other cortical sites.

In order to test this hypothesis in detail we labeled specific pontine compartments by injections of the anterograde tracer (DiI) into visual (A17) and somatosensory (SmI) areas, and projection neurons by injection of retrograde tracer (Fluorogold) into the brachium pontis. The dendritic morphology of identified pontine projection neurons was subsequently revealed by intracellular fills with Lucifer yellow in fixed slices of the PN. The results reported here provide direct support for the hypothesis that there exists a highly specific relationship between dendritic fields of projection neurons and the borders of compartments defined by cortical afferents.

\section{Materials and Methods}

Microinjections. For surgery, Lister hooded rats received an initial dose of chloral hydrate $(7 \%, 0.7 \mathrm{ml} / 100 \mathrm{gm}$ body weight). Additional doses were administered when needed. The eyes were covered with jelly in order to prevent drying. The animal was placed into a stereotaxic head holder and small trepanations (diameter circa $1 \mathrm{~mm}$ ) were drilled into the skull to allow injections of fluorescent tracers with micropipettes (tip diameter $30 \mu \mathrm{m}$ ) mounted on Hamilton syringes. In order to label cortical terminals in the PN, neocortical sites (A17, bregma -6.3, lateral 3.2; SmI(forelimb), bregma 0.5, lateral 3.4; Paxinos and Watson, 1986) received $50 \mathrm{nl}$ of the anterograde tracer DiI (5\% in dimethylformamide, Molecular Probes) injected at a depth of $1-1.5 \mathrm{~mm}$. In order to yield sufficient anterograde transport the core of the injection site needed to be located within layer 4 or 5 . As some effective injection sites hardly reached layer 5 , we assume that the dye is also taken up by the thick apical dendrites of layer 5 projection neurons (Fig. $1 C$ ). In several cases, four such injections located on the edges of a square with lateral length of $500 \mu \mathrm{m}$ were made. Projection neurons in the PN were labeled by 
injections of the retrograde tracer Fluorogold (2\% in aqua bidest., Fluorochrome Inc.) into the brachium pontis (bregma - 10.5, lateral 3.5, depth 3 ). Wounds were treated with local antibiotics. After surgery the animals were kept warm and provided with electrolytes and analgetics. All procedures followed protocols approved by the local animal care committee and the policy on the use of animals in neuroscience research approved by the Society for Neuroscience.

Preparation of slices and intracellular staining. After a survival time of 4-7 d, rats were deeply anesthetized with chloral hydrate and perfused through the aorta with cold phosphate buffer $(\mathrm{PB}, 0.1 \mathrm{M}, 100 \mathrm{ml})$ followed by cold paraformaldehyde (PFA, $2 \%, 500 \mathrm{ml}$ ) in PB. After disscction of the brain, frontal or parasagittal slices of pontine brainstem were prepared using a vibrating microtome (thickness $300 \mu \mathrm{m}$ ) and stored in cold $\mathrm{PB}$. Slices were transferred to a plastic chamber mounted on a fixed stage of a modified epifluorescence microscope (Leica) equipped with a long-distance objective $(20 \times)$. Tips of glass electrodes were bent to an angle of about $90^{\circ}$ and filled with Lucifer yellow $(5 \%$ in $0.1 \mathrm{~m} \mathrm{LiCl}$, Aldrich; electrode resistance 150-300 M $\Omega$ ). Electrode tips and retrogradely labeled cells were aligned on an ocular cross hair. Thus, the electrode tip and the cell were located along a vertical axis. By lowering the micropipette, projection neurons were impaled with high accuracy under direct visual control. As the form of the somata and even proximal dendrites could be already recognized with illumination for Fluorogold immediately before the filling, it could be easily judged whether the correct neuron had been impaled. Intracellular fills with Lucifer yellow were performed with negative square wave current $(3-10 \mathrm{nA}$ at $2 \mathrm{~Hz})$. The electrode was withdrawn when the dye began to leak out from the soma. Figure $1, A$ and $B$, shows an example of a cell retrogradely labeled with Fluorogold and intracellularly filled with Lucifer yellow.

Neocortex and cerebellum were postfixed overnight in 4\% PFA and cut to a thickness of $100 \mu \mathrm{m}$ on a vibrating microtome in order to reconstruct the injection sites. An example of a cortical injection site is given in Figure $1 C$. Neoccrtical injection sites which reached the white matter were excluded from further analysis. All cerebellar injection sites were confined to cerebellar cortex and white matter. The center of the injection sites were typically located within the brachium pontis dorsolaterally of the lateral deep cerebellar nucleus. They were usually sufficient to label retrogradely projection neurons throughout the PN.

Light microscopy and quantitative analysis. The slices were mounted and coverslipped with buffered glycerol to observe the DiI-labeled terminal fields under an epifluorescence microscope. The location and orientation of filled neurons with respect to the terminal fields was documented with photomicrographs (Kodak Ektachrome 400 or 1600 ASA) using the appropriate filter sets for Dil and Lucifer yellow, respectively (Leica N2.1 and E3). As virtually all projection neurons exhibited dendritic appendages, the quality of fill was judged by examining the dendritic appendages located on distal dendrites. Cells werc included in the analysis when their distal dendritic appendages were clearly visible. Furthermore, cells with cut dendrites were discarded. Small cells were drawn without further cutting the slice using a $63 \times$ oil-immersion objective and a camera lucida. Larger cells were drawn after cutting the slice on a freezing microtome to sections of $80 \mu \mathrm{m}$ thickness.

Photomicrographs of Dil-labeled terminal fields were converted to digital gray-scale images (pixel size, $2 \times 2 \mu \mathrm{m}$ ) using a slide scanner (Microtek), and thereafter low-pass filtered by a two-dimensional moving average filter (kernel, $5 \times 5$ pixels). The $50 \%$ gray value between the maximum gray level within the terminal field and the minimum gray level of the unlabeled part of the PN was taken as the border of the terminal field and printed (Fig. 2). The magnification factor of the printouts was adjusted so as to match that of the drawings of the filled celts. The photomicrographs of terminal fields and Lucifer yellow-filled cells with appropriate magnification were used as reference to superimpose drawings of borders and cells onto each other.

In order to test whether the dendrites of projection neurons respect the borders of terminal fields, the area of the dendritic field was approximated by a polygon connecting the distal ends of the dendrites (see Fig. 8). The connections were drawn obeying the following rule. A dendritic ending (minimum length, $15 \mu \mathrm{m}$ ) was connected by a straight line to the one lying next to it. Crossing proximal dendrites with connecting lines was avoided. Thus, if two neighboring dendritic endings were separated by a third dendrite, their connection was indirect via the ending of the intervening dendrite. An estimate of a dendritic field which does not respect any border and therefore can be assumed to be radially organized was achieved by drawing a circle with the same area as the polygon around the soma. The overlap area of the polygon and the circle with the neighboring compartment was measured using a digitizing tablet. The difference of the overlap area of the polygon minus the overlap zone of the circle was taken as a measure of the avoidance of the neighboring compartment. Significance was tested using the Wilcoxon Signed Rank Test.

Double anterograde labeling. In order to investigate the topographic arrangement of corticopontine projections, the anterograde tracers DiI and DiAsp (5\% in dimethylformamide, Molecular Probes) were used to double label terminal fields in the pontine nuclei originating from different sites within the same cortical area in five rats. Two microinjections (one with DiI, the other with DiAsp; $50 \mathrm{nl}$ cach) displaced by less than $1 \mathrm{~mm}$ were placed stereotaxically in A17 or the forelimb area of Sml. Perfusion was performed with $4 \%$ PFA. The brain was postfixed overnight and cut to a thickness of $100 \mu \mathrm{m}$ using a vibratome. The sections were mounted and coverslipped with buffered glycerol and examined under an epifluorescence microscope. Reconstructing the injection sites as well as digitizing and evaluating the locations and sizes of anterogradely labeled terminal fields was performed as described above. The size of the terminal fields labeled with DiI and DiAsp and their overlap areas were measured using a digitizing tablet. As a control, anterograde label in the superior colliculus was processed in the same way since the corticotectal projection is known to be topographically organized (Huerta and Harting, 1984). The pattern of anterograde label in the superior colliculus was also used to confirm the location of injection sites. As described in the Results, it was consistent with carlier reports studying tectal representation of visual and forelimb somatosensory information (Dräger and Hubel, 1976; Wise and Jones, 1977; Huerta and Harting, 1984).

\section{Results}

The fine dendritic morphology was similar in all projection neurons examined. Spine-free thick proximal dendrites branched into several thin daughter dendrites which in turn branched profusely (Figs. 2-7). The thin distal dendrites were always covered irregularly with spine-like processes and dendritic appendages. A description of the general aspects of the dendritic morphology of pontine projection neurons and their comparison with neurons labeled with the golgi technique (Mihailoff et al., 1981a) will be given elsewhere (Schwarz and Thier, unpublished results). However, the shapes and sizes of the dendritic fields varied considerably. A specific feature of these cells was that they were often elongated along the border of the nucleus, suggesting that such cells are able to respect the borders of the nucleus. However, the border of the nucleus was not the only factor determining the asymmetric shape of dendritic fields. Even in the center of the PN, highly asymmetric cells could be found, a finding which will be examined in more detail in the following sections.

DiI patches labeled from visual and somatosensory cortex were found at locations in the PN which are in accordance with previous reports (Burne et al., 1978; Mihailoff et al., 1978; Wiesendanger and Wiesendanger, 1982). Terminals labeled from the visual cortex were found in the lateral and dorsolateral portion of the PN. Typically three or four patches of label were located near the brachium pontis. Terminal fields from the forelimb area of SmI were located mostly in the ventral portion of the PN.

\section{Dendritic fields of projection neurons in the vicinity of terminal fields}

The combination of intracellular fills with anterograde tracing revealed that the asymmetry of dendritic fields noted above results from the fact that projection neurons in the PN respected the borders of the cortical terminal fields. There was no difference whether the cells were filled in frontally or parasagittally cut slices.

Figures 2 and 3 show photomicrographs and drawings, re- 

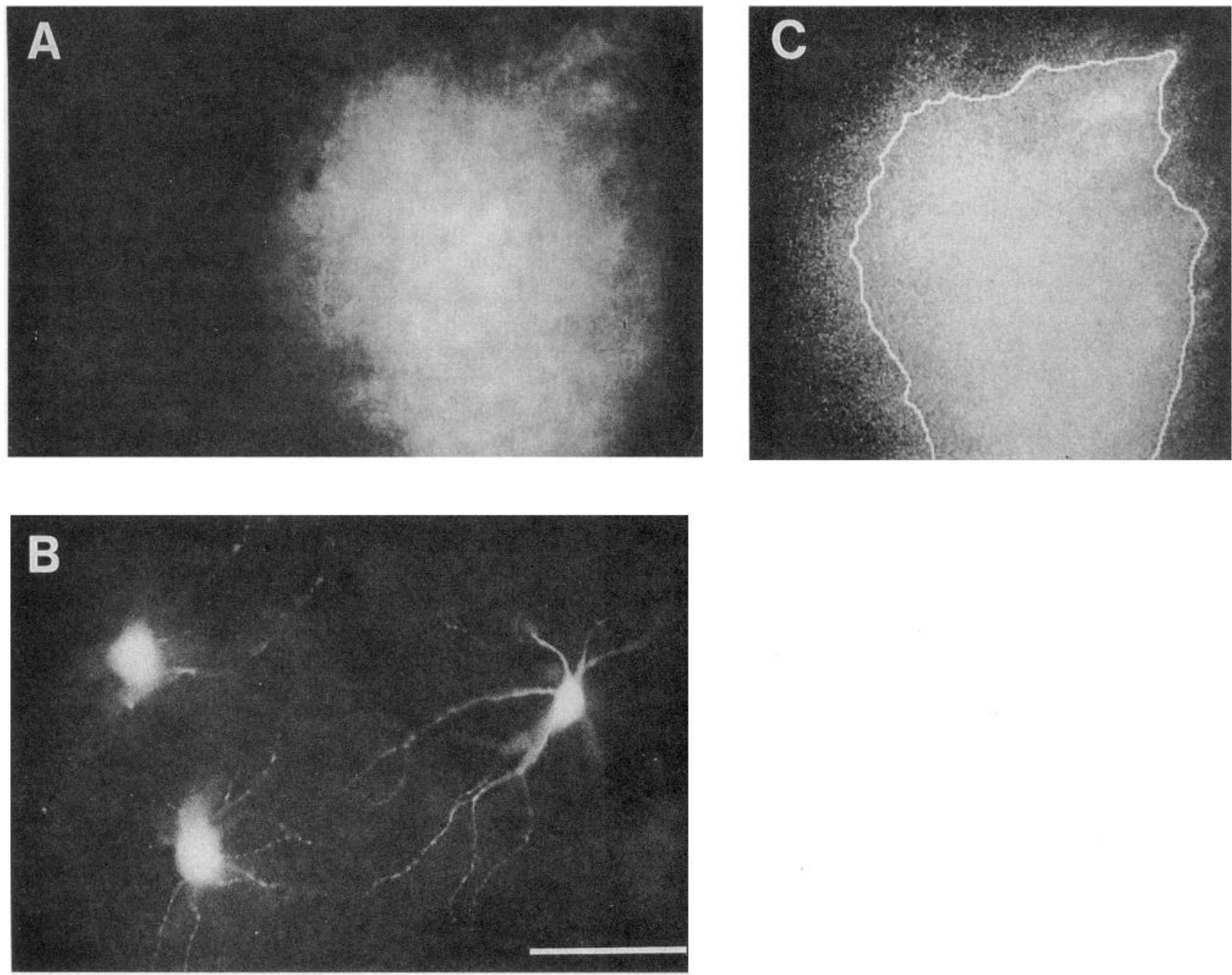

Figure 2. Photomicrographs demonstrating three projection neurons filled with Lucifer yellow in the vicinity of a DiI-labeled terminal field from $\mathrm{SmI}(\mathrm{FL})$. Note that as DiI label is destroyed by cutting with a cryotome, the slice was not further sectioned after the filling of cells. A, Illumination for fluorescence of DiI. B, Illumination for fluorescence of Lucifer yellow. For drawings of these cells, see Figure 3 . Scale bar, $100 \mu \mathrm{m}$. $C$, Quantification method applied to assess the borders of afferent fields. The raw pixel image of the afferent field in $A$ is shown superimposed on the border which corresponds to the $50 \%$ percent gray value after filtering with a two-dimensional moving average (size of the kernel $5 \times 5$ pixels; size of one pixel $2 \times 2 \mu \mathrm{m})$.

spectively, of three identified projection neurons lying near the border of a terminal field labeled from the forelimb area of SmI. The drawing in Figure 3 shows that two of the cells were located outside and one was located inside the DiI patch. The dendritic fields of the cells were elongated along the border of the terminal field and clearly did not cross it. Rather, distal dendrites of all three cells ended in the border region. Note that the cells were elongated along the ventrodorsal axis, thus the elongation could not be explained by an arrangement of the dendrites along fiber tracts which travel in a laterolateral direction in this region of the PN.

An example of a projection neuron located in the vicinity of a terminal field labeled from the visual cortex is shown in Figure 4. The soma of this neuron was located outside the DiI-labeled patch. Two of the thick basal dendrites were directed away from the border. The one which was directed toward the terminal field bent approximately at a right angle and thus did not cross the border. As in the previous case, this cell was not oriented along the fiber tracts traveling in parallel to the border of the cerebral peduncles in this region of the PN. Bending dendrites were observed in several cases (for further examples, see Figs. 6, 7).

More examples of projection neurons located within or near the terminal fields labeled from the somatosensory and visual cortices are shown in the drawings presented in Figures 6 and 7. The dendritic fields showed a great variety of forms, ranging from nearly oval or circular to very complex shapes. The somata could be located in the center of the dendritic field (Fig. 3) as well as eccentrically (Figs. 6, 7). The eccentricity of the soma could reach rather extreme values when the soma was located in the direct vicinity of the border of terminal fields (Figs. 6, 7). It is suggestive that these complex shapes are related to the borders of the terminal fields located nearby. In order to estimate to what extent the shape of dendritic fields is determined by neighboring terminal fields within our whole sample of projection neurons, we performed a quantitative analysis.

Quantitative analysis

The dependence of the shape of the dendritic field on the borders of terminal fields was analyzed in 64 projection neurons whose 


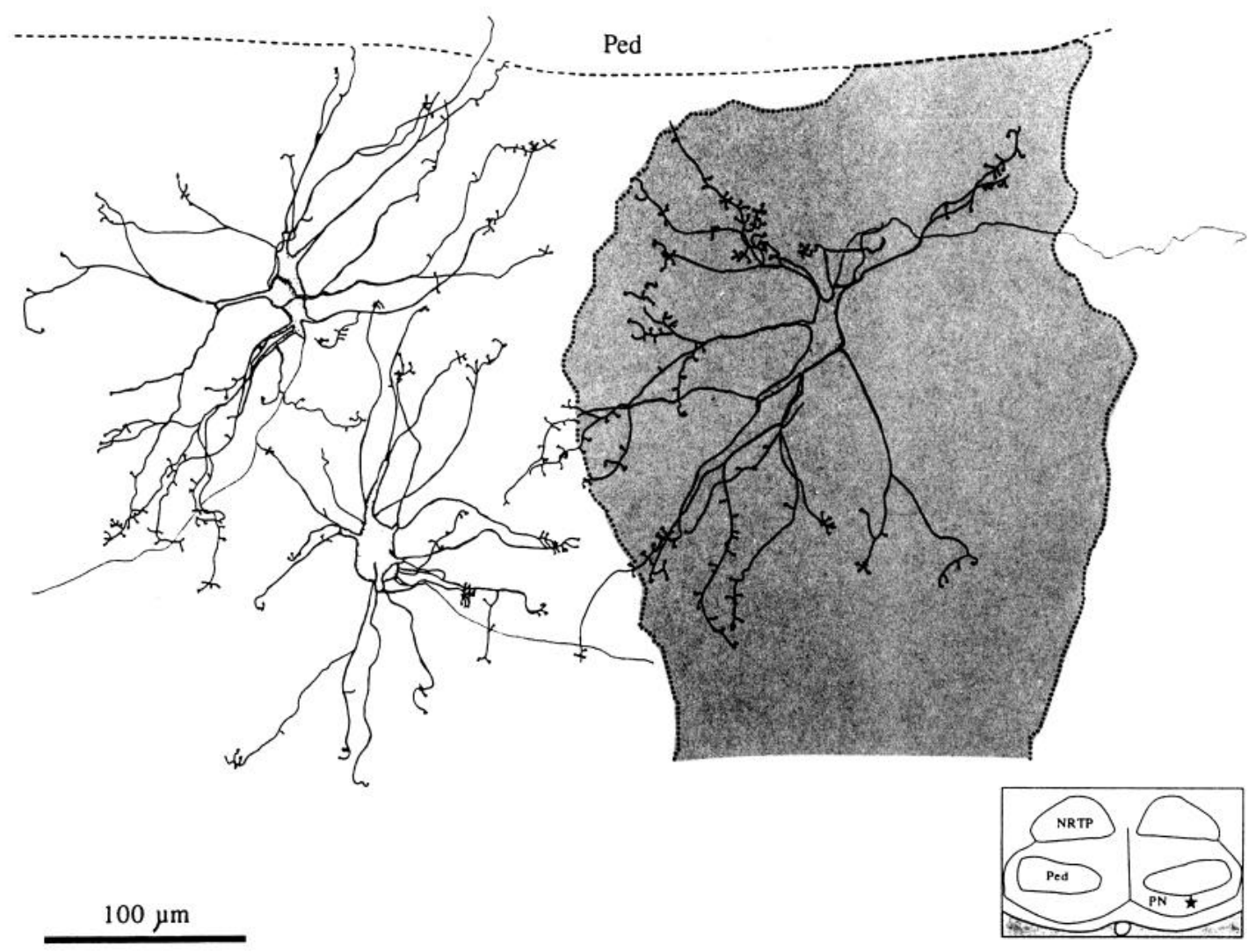

Figure 3. Drawing of the cells in Figure 2. The dendritic fields of all three cells are clearly related to the borders of the terminal field depicted in gray. Note that these cells are oriented orthogonal to the fiber bundles which travel in a laterolateral direction in this region of the PN. The star in the inset indicates the location of the cells within the PN. PN, pontine nuclei; NRTP, nucleus reticularis tegmenti pontis; Ped, pedunculi cerebri.

somata were located maximally $160 \mu \mathrm{m}$ away from the borders. As the projection neurons show a great variety of dendritic field shapes including convex and concave outlines (Figs. 2-7), fitting them by simple geometrical forms like circles or ovals is not appropriate. Similarly, borders of terminal fields displayed very complex courses and likewise could not be approximated by simple geometrical forms like straight lines or circles. We therefore approximated the dendritic fields by connecting the ends of distal dendrites to polygons as described in Material and Methods. This simple method has the advantage that no assumptions about the geometrical form of either the dendritic fields or the terminal fields are necessary. The null hypothesis is represented by a dendritic field which does not respect any borders in its vicinity. Such a dendritic field can be expected to be radially organized and therefore can be approximated by a circle around the soma. The area of the circle was chosen such as to match that of the polygon. If dendritic fields respected the borders of the neighboring terminal fields, the zone of overlap of the polygons with the neighboring compartments should be smaller than the zone of overlap with the circles.

Figure 8 shows an example of the dendritic field approximation and a diagram depicting the difference of overlap zones (polygon minus circle) as a function of the distance of the somata to the border, respectively. Differences were negative, when the cells were located near the border. This highly significant result (Wilcoxon Signed Rank Test for pairs, $p<0.0001$ ) indicates that the dendritic fields avoid the neighboring compartments.

\section{Double anterograde tracing}

The finding that dendritic fields respect borders of terminal fields from A17 and SmI is consistent with the view that the sensory maps of these areas are mapped in a fragmented way onto the PN. Previous studies have suggested that different parts of the somatosensory cortical area project to different parts in the PN (Brodal, 1968a,b; Mihailoff et al., 1978). However, these studies compared the pattern of anterograde label from distant cortical regions in different individuals and thus were not able to decide whether the topology of the cortical sensory map is maintained within individual pontine compartments. If the topographical order were maintained, neighboring sites on the cortical surface would project onto neighboring sites within the PN displaced in a defined direction. Alternatively, the mapping of the given area could be fragmented. Then a certain region of the cortical area would converge onto a single pontine compartment while distant regions would project onto different pontine compartments. Moreover, the spatial relationship of pontine compartments receiving information from neighboring cortical sites could no longer be predicted by their respective locations on the cortical map. In order to decide which of the two possible kinds of mapping is realized in the corticopontine projection, we designed experiments based on double anterograde tracing. Two different anterograde fluorescent tracers were injected into topographically neighboring sites within a single cortical area (DiI and DiAsp; distance between sites less than $1 \mathrm{~mm}$; four cases with double injection into A 17; four cases with double injection into the forelimb area of SmI). Subsequently, the size and lo- 
Figure 4. Example of a projection neuron in the vicinity of a terminal field from A17. Double exposure with filters appropriate for Lucifer yellow and DiI showing the relationship of the dendritic field with the terminal field nearby. One proximal dendrite bends in order to avoid the boundary (arrowhead). The distal dendrites then travel along the boundary (small arrows). For drawing of this cell, see Figure 5. Scale bar, $50 \mu \mathrm{m}$.

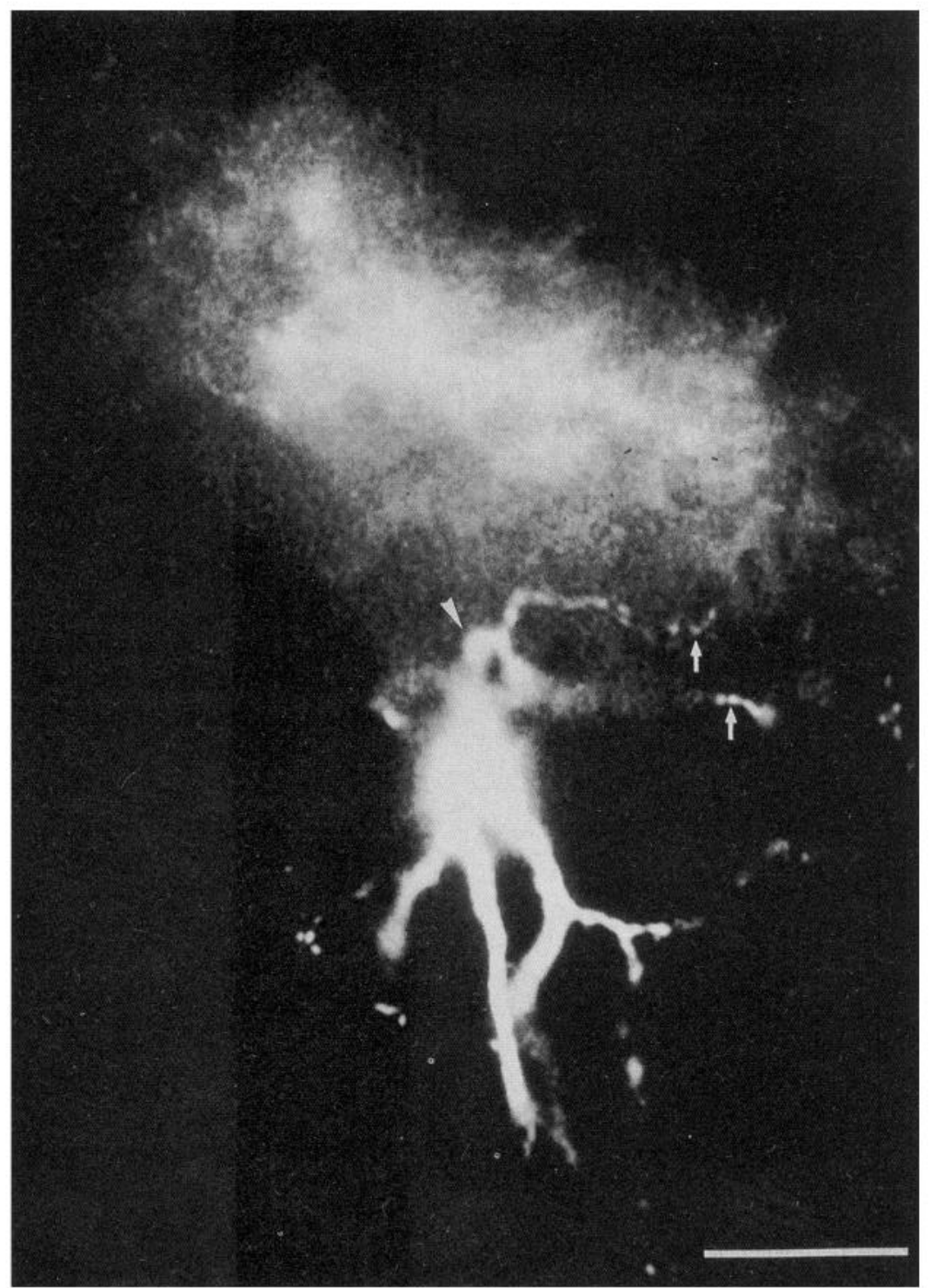

cation of the anterogradely labeled terminal fields in the PN were analyzed with the help of digitized images as described in Material and Methods. Since the topographical order of the projections from A17 and from SmI to the superior colliculus (SC) is well established (Dräger and Hubel, 1976; Stein at al., 1976; for review see Huerta and Harting, 1984), the anterograde label in the SC was used to control that the injections were topographically well separated from each other.

The photomicrographs and drawings in Figures 9-11 show examples of anterograde labeling resulting from double injections into A17 and SmI, respectively. In accordance with previous studies, the terminals of the visual cortex in the SC were found exclusively in the stratum griseum superficiale and the stratum opticum (Figs. 9, 10) (Huerta and Harting, 1984; Harvey and Worthington, 1990). This indicates that all injection sites were located within A17 as cortices subserving other modalities as well as visual areas 18 and $18 \mathrm{a}$, which surround area 17 in the rat, project to deeper layers of the SC (Sefton and Dreher, 1985; Harvey and Worthington, 1990). In all cases the afferent label was located in the lateral part of the SC representing the lower part of the visual field (Sefton and Dreher, 1985). Like- wise in line with previous findings the forelimb somatosensory cortex was found to project to the stratum griseum intermedium of the lateroposterior portion of the SC. Often faint label in register with that in the stratum griseum intermedium was found in the underlying stratum album intermedium (Dräger and $\mathrm{Hu}-$ bel, 1976; Wise and Jones, 1977; for review see Huerta and Harting, 1984). In some cases a patchy distribution of anterograde label was detected (Fig. 11) (Wise and Jones, 1977). For the quantitative analysis we exclusively used the bright label in the stratum griseum intermedium. The anterogradely labeled afferent fields in the SC were in all cases well separated from each other and showed only minor overlap, indicating that the cortical injection sites had been made in places representing adjacent but different topographic sites on the sensory surface. Furthermore, the afferent fields labeled with the two dyes showed a systematic shift within the SC. Thus, in every section the two dyes were displaced in the same direction, as was expected given the fairly good point to point connection of the corticotectal projection system (Dräger and Hubel, 1976; Stein et al., 1976). In marked contrast to the distribution of label in the SC, the afferent label in the PN of the same animal displayed a very different and 


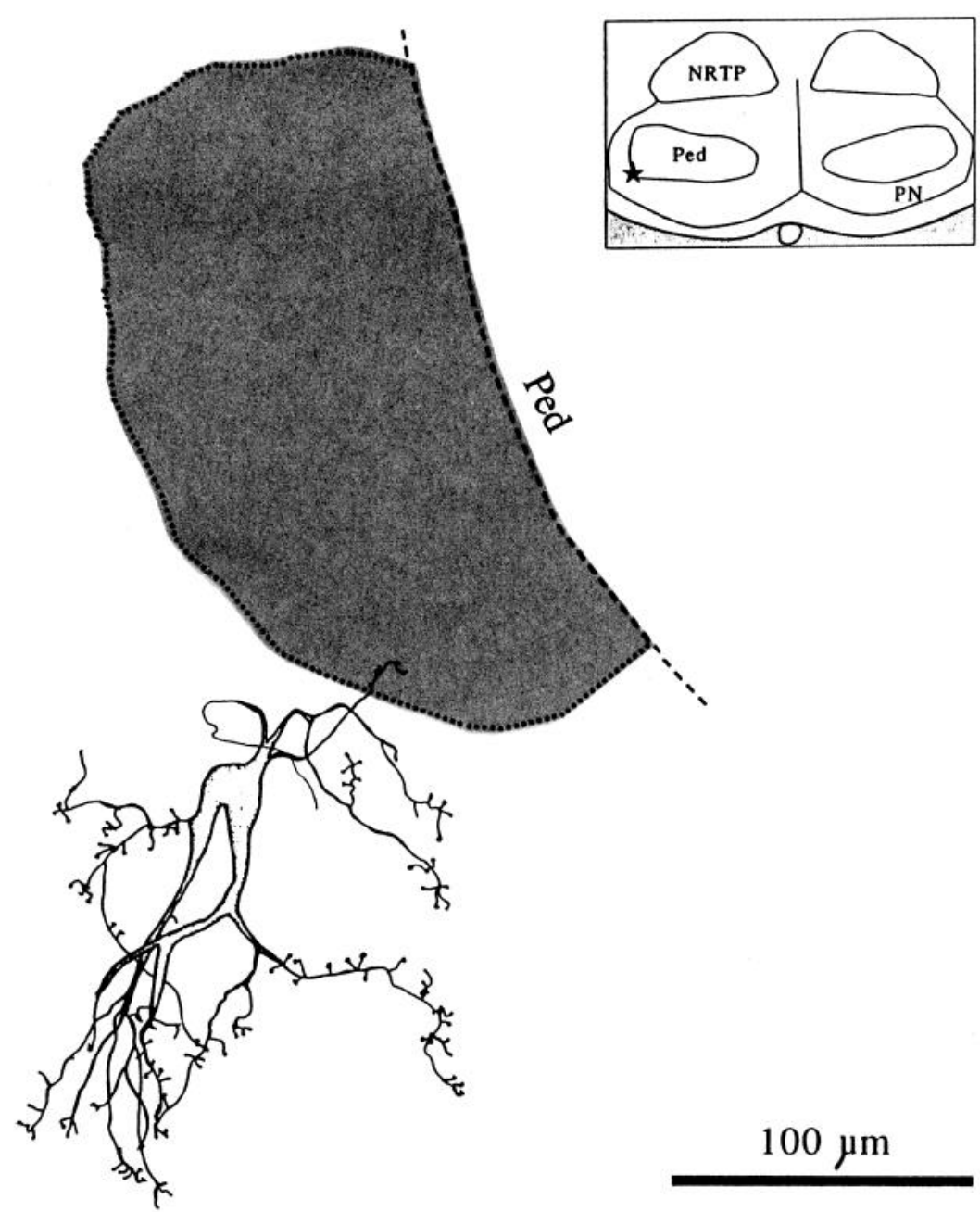

Figure 5. Drawing of the cell and the terminal field shown in Figure 4. For purpose of illustration the cell was rotated with respect to Figure 4. Two of the three thick proximal dendrites are directed away from the border. The one which was directed toward the border bends in order to avoid crossing the boundary. Note that the dendritic field is not elongated along the fiber bundles which travel parallel to the border of the cerebral peduncle. Conventions are as in Figure 3. more complex pattern of termination. The two dyes typically labeled two to four terminal fields in the PN (Figs. 9, 10). Consistent with previous reports, label was found in the PN at lateral to dorsolateral sites for injections in A17 and lateral to ventral sites for injections in SmI (Burne et al., 1978; Mihailoff et al., 1978; Wiesendanger and Wiesendanger, 1982). Compared to the label in the SC, the label of the two anterograde dyes overlapped extensively in most cases. However, the terminal fields labeled with the two dyes were not in all cases totally congruent. Often a small terminal field labeled with one dye was included within a larger one labeled by the other. In some sections, a shift of two labeled fields was observed (Figs. 9, 11), but in no case was this a consistent feature found in all sections which included the respective columnar structure. In some cases a columnar structure was found, which was labeled exclusively with one dye along its entire rostrocaudal extent (Figs. 9, 10). As the injection sites were neighboring in the cortex, it follows from these findings that the number and the size of patches increase with the size of cortical area which was injected. However, double anterograde labeling emphasizes that this increase is not due to an orderly shift of pontine patches according to the location of the injection sites within the cortical map, as is the case for patches in the superior colliculus. Rather, this enlargement seems to result from an incorporation of additional discrete pontine fragments into the labeled area.

To give a quantitative estimate of these results, we measured the areas of the terminal fields labeled by both dyes and calculated the percentage of their overlap areas for every distinct pontine terminal field and for every section, and compared them to the same measures taken from anterograde label within the SC.

The diagram in Figure 12 plots the amount of overlap of terminal fields labeled with one of the two dyes with terminal fields labeled with the second dye for both the PN and SC. Terminal fields in the PN that were labeled by only one dye are not included in the analysis. In most cases, the overlap zones of terminal fields in the PN labeled with both of the dyes were clearly larger than those seen in the SC. It is also evident that not all cases showed a total overlap of the two dyes. As indicated by the dots along the lines representing overlap of $100 \%$ for each dye, quite frequently a relatively small afferent field labeled by one of the dyes was totally included in a larger afferent field labeled by the other.

\section{Discussion}

We investigated the relationship of dendritic fields of identified projection neurons to the terminal field of afferents originating from cortical areas A17 and $\mathrm{SmI}(\mathrm{FL})$ in order to gain insight into the way the topological representation of sensory surfaces in the neocortex is transformed into the highly fractured representation present at the level of the cerebellum. We found that the form of the dendritic fields of pontine projection neurons 


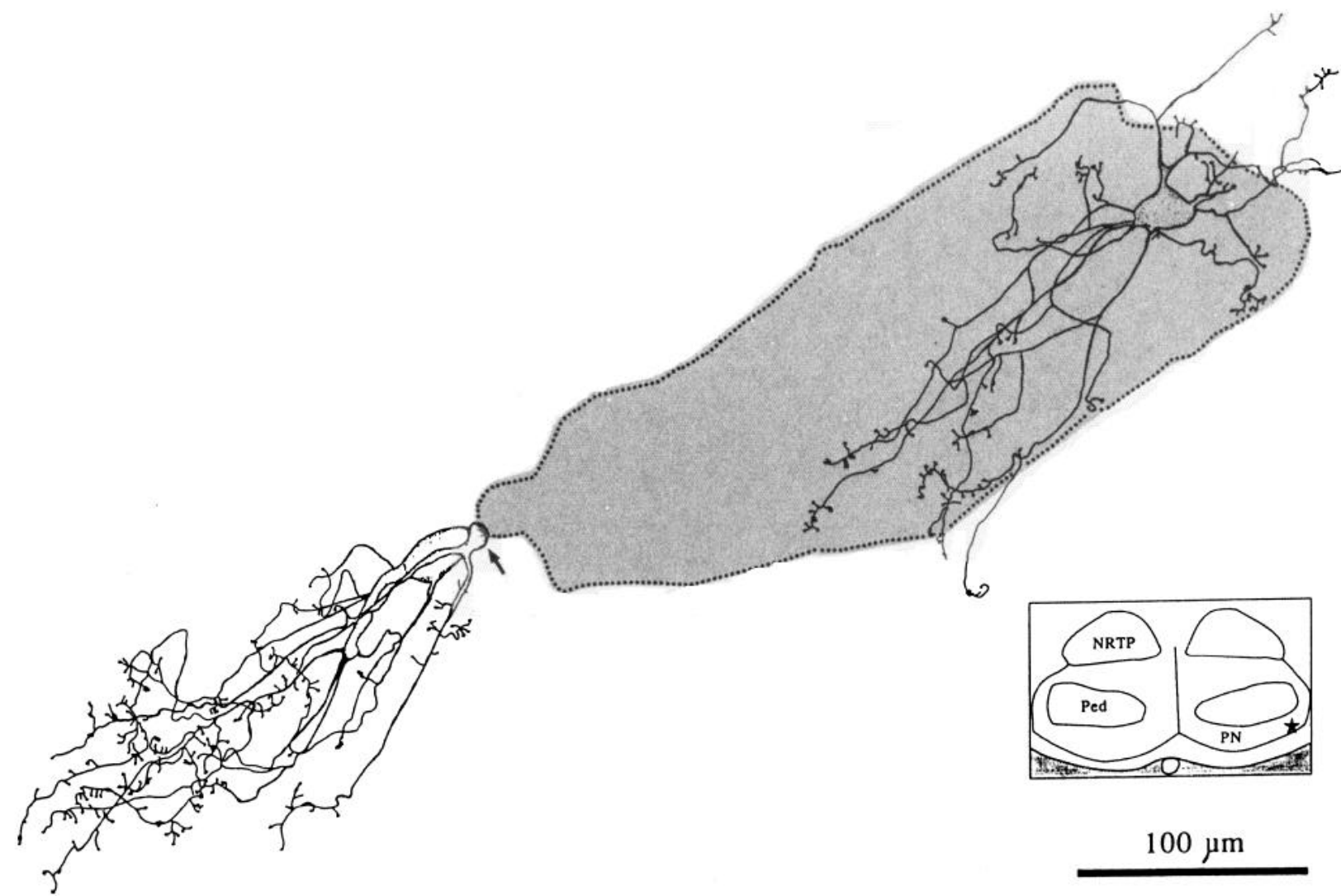

Figure 6. Drawing of two projection neurons in the vicinity of a terminal field labeled from SmI(FL). The cell on the bottom left demonstrates the deformation of a dendritic field characterizing a cell whose soma is located directly on the border. In this case one dendrite bends at an angle of about $180^{\circ}$ in the plane orthogonal to the section in order to project away from the neighboring terminal field (arrow). Therefore, the soma is observed in an extremely eccentric location within the dendritic field. Note that the cells are elongated along the fiber bundles traveling in parallel to the middle cerebral peduncle (from bottom left to upper right). However, both neurons respect those borders of the terminal field that are oriented orthogonal to this direction (bottom left and upper right side of the terminal field). Conventions are as in Figure 3.

was found to be highly dependent on the cortical afferent fields. Dendrites of projection neurons did not cross the borders of terminal fields and they even bent in order to avoid crossing the boundary. Double anterograde labeling from adjacent sites in A17 and $\mathrm{SmI}(\mathrm{FL})$ revealed that the corticopontine projection displays substantially less topographic arrangement as compared to the corticotectal projection. On the other hand, there was no total overlap of terminal fields on the level of the PN; rather, a complex pattern of overlap and nonoverlap was observed. These findings suggest that the $\mathrm{PN}$ is divided into modules providing segregation of information from different cortical regions. With this spatial arrangement the corticopontine projection could make a substantial contribution to the transformation mentioned above. Before discussing this possibility we will first consider possible methodological artifacts which may have contributed to the results.

\section{Methodological considerations}

Intracellular fills. It might be argued that the observed asymmetry of the dendritic fields is due to cut dendrites, an artifact introduced by intracellular filling of neurons in slices. The major argument backing our conclusion that the observed asymmetry is a real characteristic of pontine projection neurons is the specific relationship of the dendritic fields to the borders of terminal fields located nearby. Artifacts introduced by cutting dendrites would be expected to be unspecific with respect to their spatial relationship to local borders. Another strong argument against the possibility that eventual missing of cut dendrites may be the reason for our results is the observation that in several cases bending, rather than terminating, dendrites were the cause of asymmetric dendritic fields.

Double anterograde labeling. In our experiments based on double labeling of corticopontine afferent fields, the overlap between terminal fields labeled with DiI and DiAsp was extensive. It may be argued that the sensitivity of the detection of the dyes was not appropriate to discriminate nonoverlapping parts of the terminal fields. A strong argument against this view is our finding of displaced anterograde label in the SC. It clearly demonstrates that the two dyes are well suited to discriminate nonoverlapping terminal fields (Fig. 9A,B). Furthermore, the finding that in several cases a pontine terminal field was labeled by only one tracer along the whole extent (Figs. 9, 10) and that a certain shift of the labeled fields was observed in some cases (Figs. 9, 11 ) is not compatible with the view that the pattern of terminal fields observed is due to poor discrimination between the two dyes. On the other hand, a certain asymmetry inherent in the physical detection of the two dyes must be taken into consideration. The emission spectrum of the fluorescent tracer DiI is very narrow, while the one of DiAsp is broader and overlaps to a certain extent with that of DiI (Loew and Simpson, 1981). Even with optimal filtering for excitation and emission of both dyes there is some overlap of the two emission spectra. Therefore, in cases of very dense DiAsp labeling the size of the terminal fields labeled with DiI may be slightly overestimated. In 


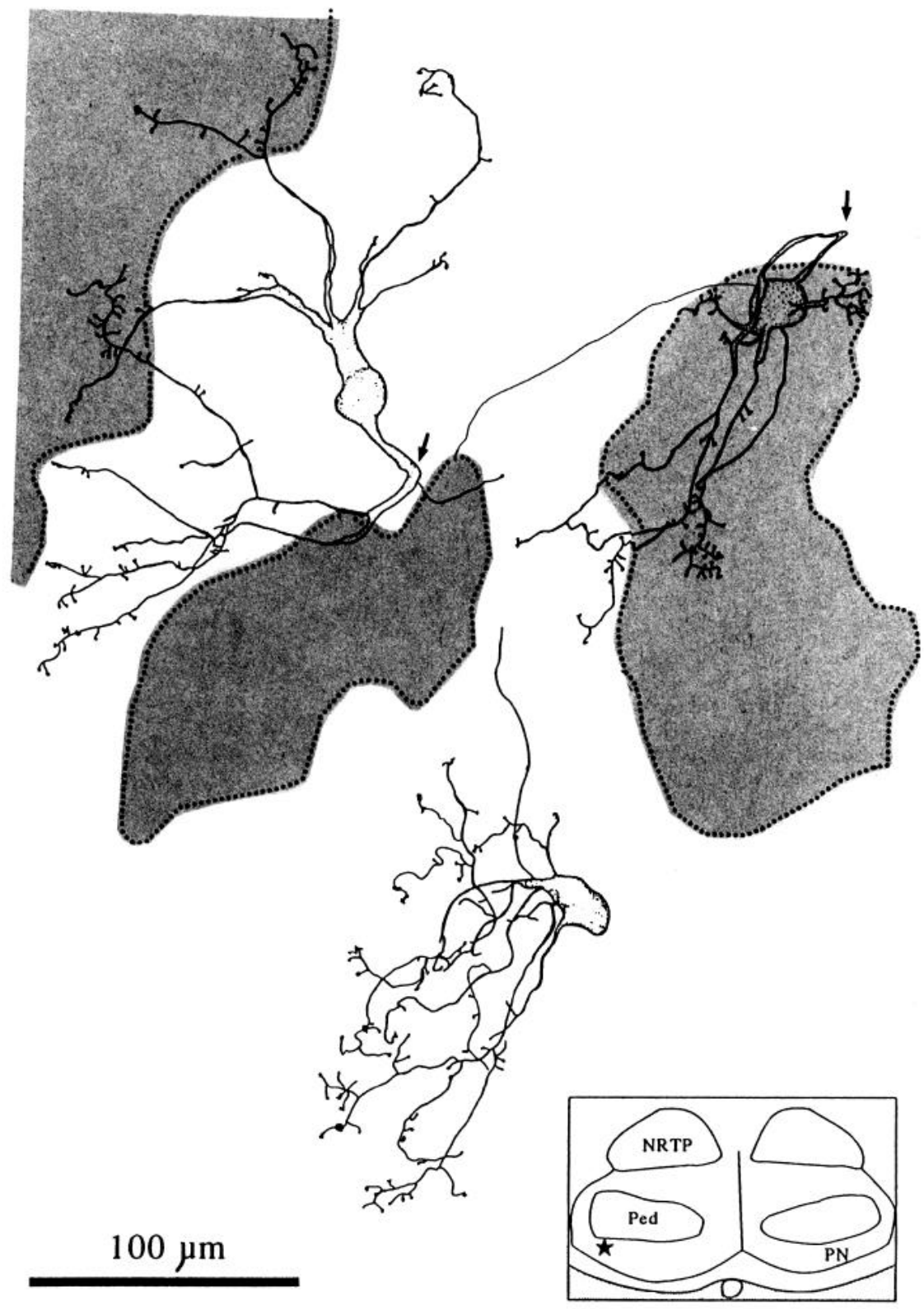

Figure 7. Drawing of three projection neurons labeled in the vicinity of several terminal fields originating from A17. These cells demonstrate that even cells in the space between terminal fields labeled from the same cortical injection may respect the borders of the compartments. Note the bending dendrites of the two dorsal cells (arrows) and the eccentric location of the soma within the dendritic field of the cell in the dorsal right. Conventions are as in Figure 3.

Figure 12 this is observed as a tendency of the data points to be shifted to the upper left side of the diagram. Often, DiIlabeled fields totally include fields labeled by DiAsp. Nevertheless, as we also observed the reverse-terminal fields labeled with DiAsp which totally included fields labeled with DiI-this phenomenon cannot be related exclusively to the asymmetry in the detection of the two tracers. Taken together, our finding that terminal fibers of neighboring cortical sites largely converge onto the same compartments within the PN and show a complex pattern of overlap and nonoverlap reflects the qualitative aspects of the corticopontine projection quite correctly despite a slight tendency to overestimate the area of DiI-labeled fields.

\section{Structural basis of pontine compartments}

The present results show that borders of presynaptic as well as postsynaptic elements are very precisely confined to a common compartment. The question arises as to how this precision is achieved: are the common borders determined by the afferent fibers and postsynaptic dendrites themselves, or does a third fac- tor exist which divides the pontine tissue into compartments? Studying the cytoarchitecture of the PN, Mihailoff et al. (1981a) and Mihailoff and McArdle (1981) have reported that there are no spatial differences in the composition of cytological elements across the PN. A certain region, however, was observed to be walled off by fascicles of pontocerebellar neurons (Mihailoff et al., 1981a). Actually, in some instances when attempting to fill neurons we penetrated thick axons which always were directed in parallel to the borders of the cerebral peduncle or the brachium pontis (Schwarz and Thier, unpublished observations). Such fiber bundles could possibly result in a segmentation of the pontine nuclei, thus creating borders which are respected by both cortical terminals and dendritic fields. If this were the case, a relationship of dendritic fields and afferent fields would be expected only along the orientation of these fiber tracts. However, contrary to this expectation, we found cells respecting borders of terminal fields which were oriented along this axis (Fig. 6) as well as perpendicular to it (Figs. 3, 5-7). We therefore conclude that fiber bundles are not sufficient to explain the ob- 

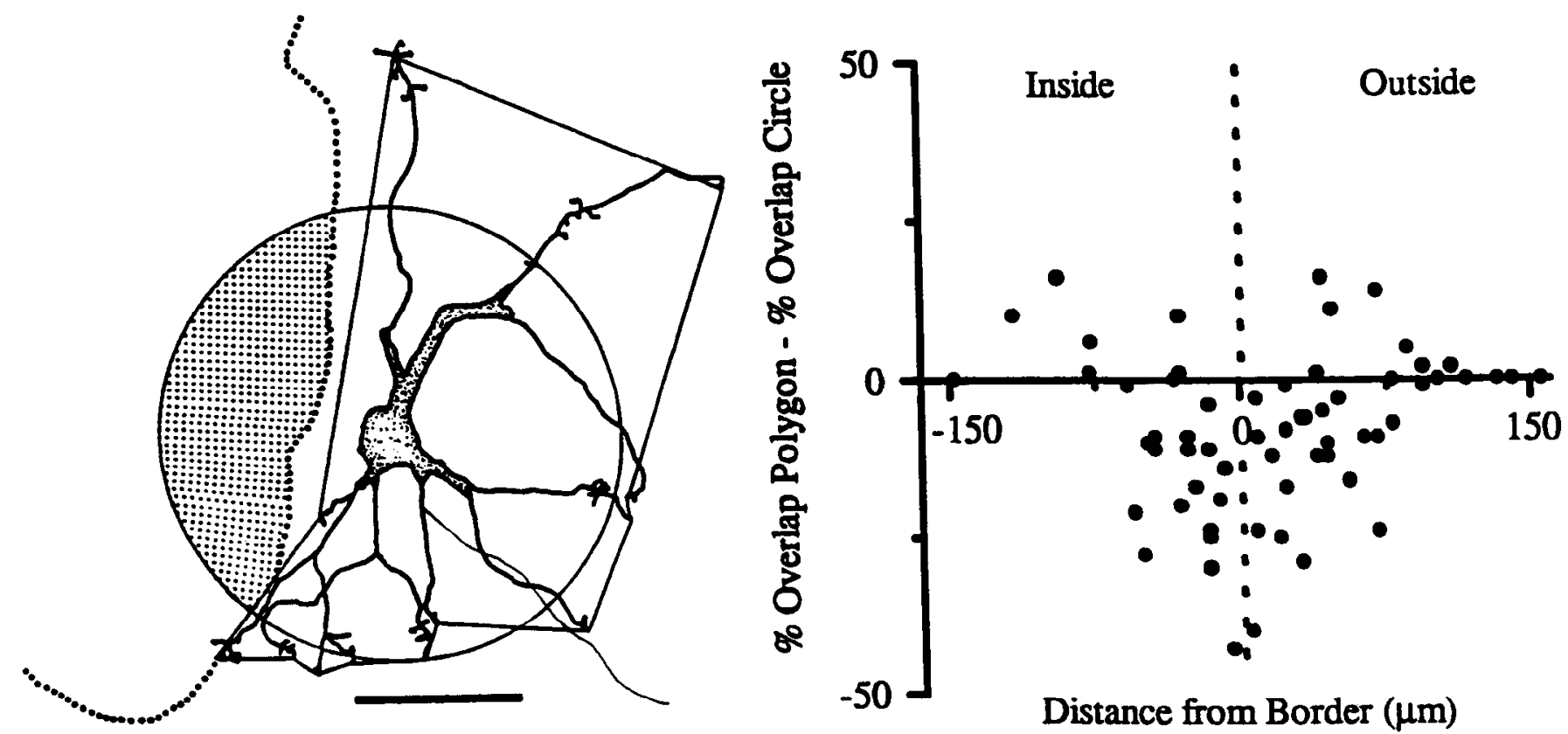

Figure 8. Quantitative analysis. Left, Example of approximation of the dendritic field. The area of dendritic fields was estimated by areas of polygons connecting all dendritic endings which were longer than $15 \mu \mathrm{m}$. Whenever possible, connections which crossed dendrites were excluded. In order to approximate a dendritic field whose shape would be unaffected by the border of a terminal field, a circle with the same area as the polygon was centered on the soma. The sizes of the overlap zones of polygon (none in the present example) and circle (dotted) with the ncighboring compartment (border of which is indicated by the large dots) were compared. See Material and Methods for further details. Scale bar, $50 \mu \mathrm{m}$. Right, Diagram showing the difference of relative overlap (polygon minus circle) plotted against the distance of the somas to the border. Differences are negative when the cells are located near the border. This clearly indicates that the dendritic fields avoid neighboring compartments $(p<0.0001$, Wilcoxon Signed Rank Test). Note that zones of overlap were chosen so as to yield a negative number if the dendritic field avoided the border. Thus, with neurons whose somata were located outside the patch the part of the polygon/circle extending into the patch was measured, while with neurons whose somata were located inside the patch the part of the polygon/circle extending into the neighboring unlabeled region of the PN was assessed.

served relationship between the cortical terminals and the pontine projection neurons.

If pontine compartments are determined by pre- and postsynaptic elements alone without being guided by a third element, a likely mechanism is the refining and focusing of the distribution of synaptic elements during development, as was shown to exist in several other projection systems in the brain (for review see O'Leary and Koester, 1993). Some support for this view was provided by a study investigating the postnatal development of corticopontine fibers (Mihailoff et al., 1984). These authors showed that during an early postnatal period the corticopontine projection is laid down in a diffuse fashion and is subsequently refined to the patchy pattern seen in adults.

\section{How is a single cortical area mapped onto the PN?}

Double labeling of cortical terminals originating from adjacent topographical locations within one cortical area revealed a substantial overlap of the respective terminal fields in the PN. On the other hand, we found largely nonoverlapping terminal fields in the SC which displayed a consistent shift with respect to each other. Thus, there is a loss of topographic arrangement in the corticopontine projection when compared to the corticotectal projection. In line with these results, there is considerable evidence from single unit studies that visual as well as somatosensory receptive fields in the PN are very large. A high percentage of visually responsive pontine neurons in cats and monkeys display receptive fields covering huge parts of the visual field which in most cases include the center of gaze (cat: Baker et al., 1976; monkey: Thier et al., 1988; Suzuki et al., 1990). Furthermore, the retinotopic location of the receptive fields and the field sizes are not related to a topographically ordered location of a given unit within the dorsolateral PN in rhesus monkeys (Suzuki et al., 1990). Similarly, pontine neurons which respond to stimulation from sensorimotor cortical areas or to tactile stimuli often display large receptive fields covering one entire limb (Rüegg and Wiesendanger, 1975; Rüegg et al., 1977).

Our results not only suggest a strong tendency of neighboring cortical sites to converge onto one pontine compartment; they also point to a complex pattern of overlap and nonoverlap in the corticopontine projection system. As described in the preceding section, large terminal fields labeled by one dye frequently included a smaller one labeled by the other dye. Furthermore, in several cases terminal fields labeled by only one dye or a certain displacement between the terminal fields were detected (Figs. 9, 10). These nonoverlapping parts of terminal fields varied along the extent of the compartment. Typically, in neighboring sections different patterns of overlap and nonoverlap could be observed (Fig. $11 B$ ). Moreover, different columnar structures included in the same section could show quite different patterns of overlap (Figs. 10B, top; $11 B$, scctions 8-10). Somc observations pointing in the same direction were made by Brodal et al. (1991) using a combination of anterograde tracing with WGA-HRP and the degeneration method in the cat. Injection and lesion at neighboring locations in the cingulate cortex resulted in a complex pattern of overlapping and nonoverlapping pontine terminal fields. Although the authors give no quantitative estimate, the 

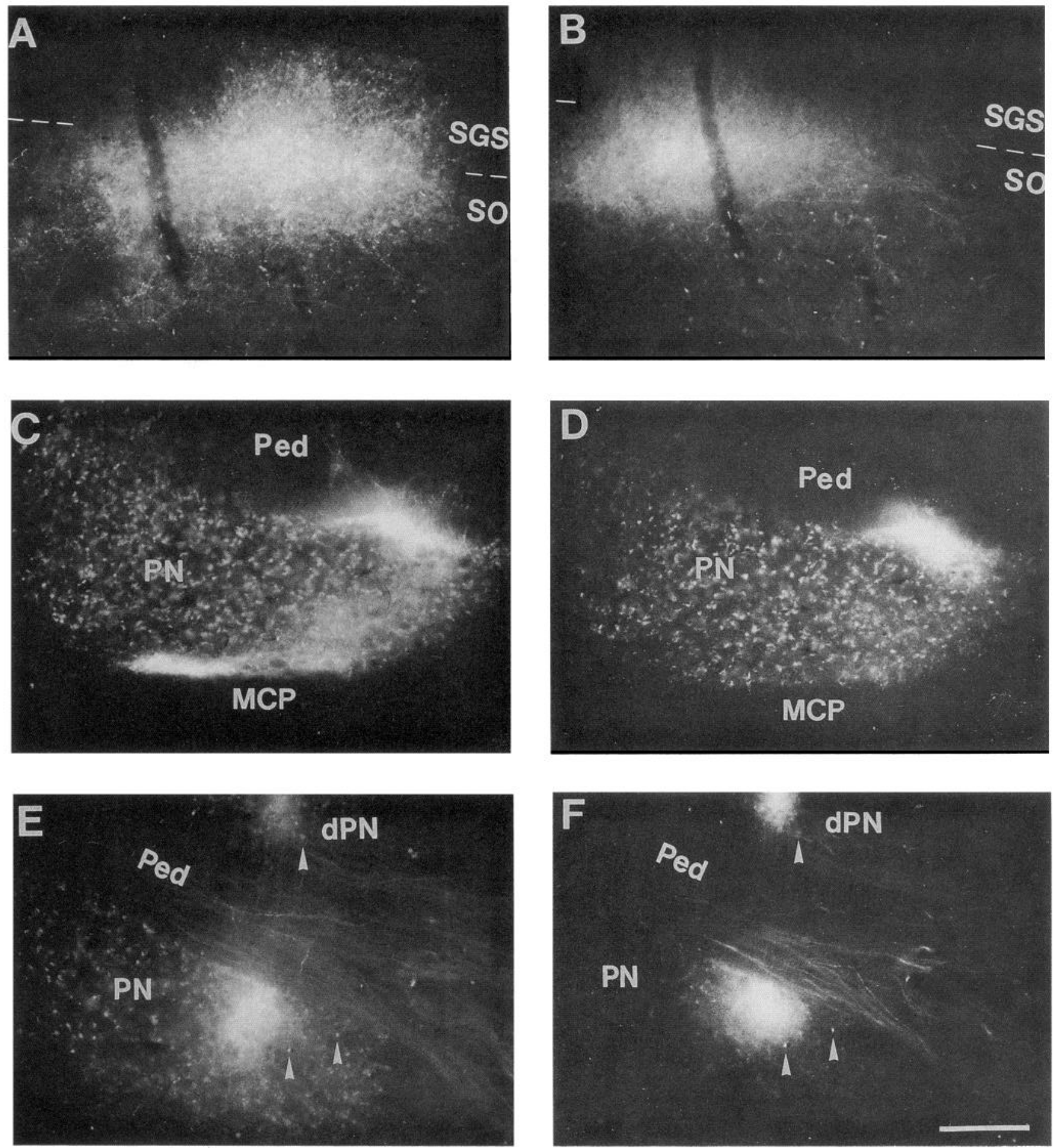

Figure 9. Double anterograde tracing from A17. A, Photomicrograph of a frontal section of the SC demonstrating a terminal field labeled with DiI from A17. The label is located within SGS and SO. B. Same section but illuminated for fluorescence of DiAsp injected at a distance of 800 $\mu \mathrm{m}$ from DiI into A17. The DiAsp-labeled terminal field only partially overlaps with that labeled by DiI, indicating that parts of the visual area were injected which represented adjacent but different regions in the visual field. $C$, Parasagittal section demonstrating DiI-labeled terminal fields in the PN of the same animal. Two compartments in the caudal part of the PN are shown. The ventral one is elongated along its rostrocaudal extent. $D$, Same section but illuminated with filters appropriate for fluorescence of DiAsp. The dorsal patch overlaps extensively with that seen with DiI. The ventral columnar structure seen with DiI is not labeled by the injection with DiAsp. $E$, Parasagittal section demonstrating DiI-labeled terminal fields traced from SmI in a different animal. Two compartments, one in the ventral, the other in the dorsal part of the PN, are shown. $F$, Same section, but illuminated for fluorescence of DiAsp. DiAsp and DiI patches overlap extensively. However, as indicated by the arrowheads pointing to distinct background fluorescence seen with both illuminations, the DiI and DiAsp patches in the ventral PN show a certain displacement with respect to each other, whereas those in the dorsal PN overlap nearly totally. For a drawing for $A-D$, see Figure 10 ; for $E$ and $F$, see Figure 11 . $M C P$, middle cerebellar peduncle; $P N$, pontine nuclei; $d P N$, dorsal part of PN; $P e d$, cerebral peduncle; $S G S$, stratum griseum superficiale; $S O$, stratum opticum. Scale bar, $200 \mu \mathrm{m}$. 


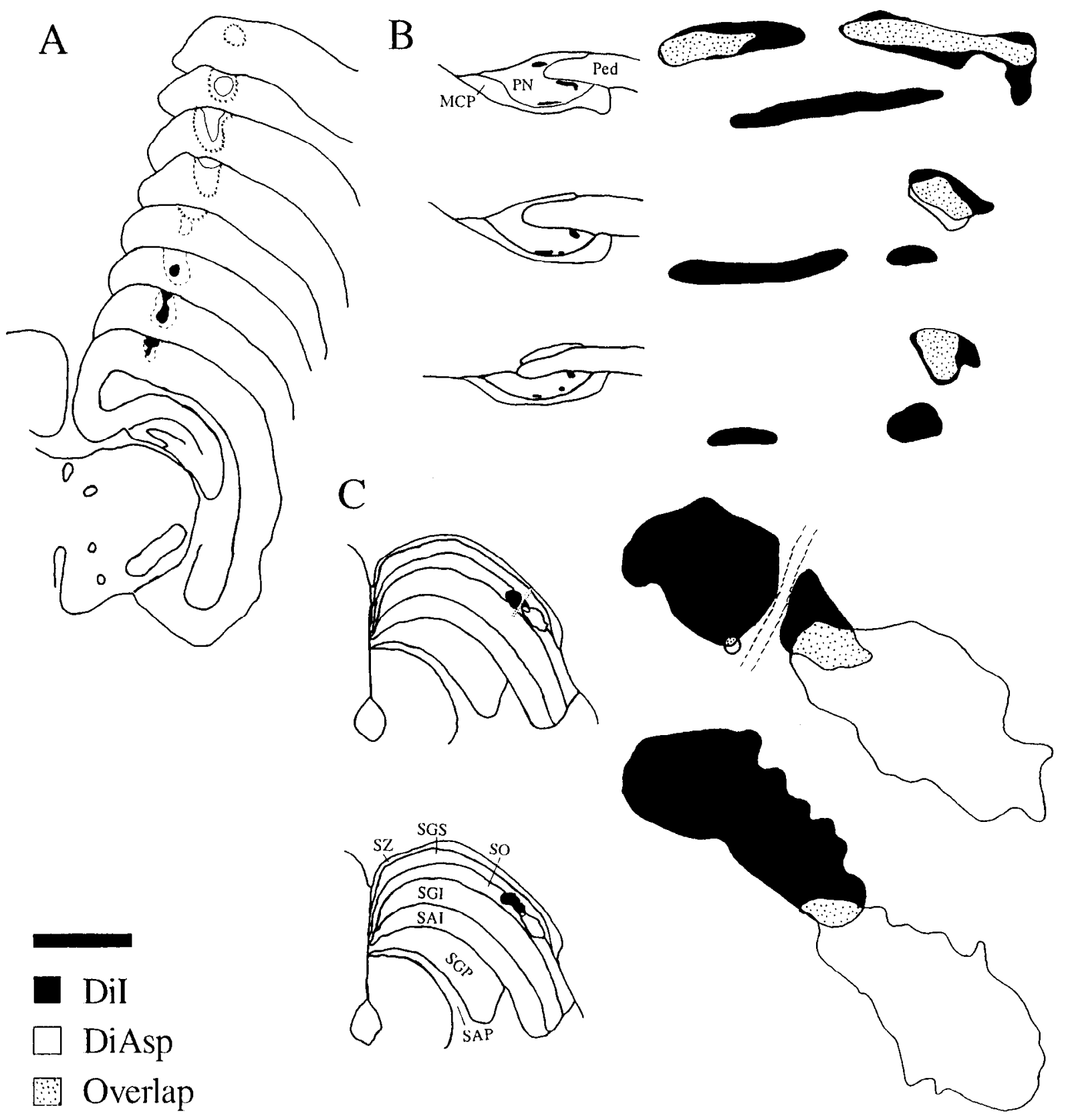

Figure 10. Drawing of the double anterograde label of the case shown in Figure $9 \Lambda-D . \Lambda$, Injection sites of DiI and Di $\Lambda$ sp in $\Lambda 17$. The dashed and crossed lines depict the halo of label around the injection sites for DiI and DiAsp, respectively. The first section is at bregma - 5.5. The sections are ordered from frontal to caudal. $B$, Label in parasagittal sections of the PN. On the left side, the localization of the label within the PN is shown. On the right side, the distribution of DiI and DiAsp is shown enlarged. The terminal fields labeled with the two dyes overlap extensively in the dorsal patches. The columnar structure located ventrally is labeled only with DiI. In order to improve the graphical presentation, the distances between patches found in distant sites of the PN were not drawn in correct proportion on the right side. C, Label in frontal sections of the SC. Terminal fields are exclusively located in the lateral part of the SC in the SO and SGS. As neighboring areas of Al7 project to different layers in the SC, this indicates that both injection sites were well within A17. The enlarged drawing of the terminal fields demonstrates that they are well separated from each other and show a consistent shift with respect to each other. Sections are separated by $200 \mu \mathrm{m}$ in $A$ and $C$, $100 \mu \mathrm{m}$ in $B$. $M C P$, middle cerebellar peduncle; $P N$, pontine nuclei; $P e d$, cerebral peduncle; $S Z$, stratum zonale; $S G S$, stratum griseum superficiale; $S O$, stratum opticum; $S G I$, stratum griseum intermedium; $S A I$, stratum album intermedium; $S G P$, stratum griseum profundum; $S A P$, stratum album profundum. Scale bars: $A, 3.3 \mathrm{~mm} ; B$ and $C, 1.5 \mathrm{~mm}$ for sections and $160 \mu \mathrm{m}$ for terminal fields.

terminal fields found in their study seem to be more segregated than those observed in the present study. It seems difficult to relate this difference to a single factor, as the authors studied a different species and investigated the projection to the PN from a different cortical area. Moreover, differing sensitivities of the two tracing methods used, in conjunction with relatively large distances between the injection and lesion sites, may well have contributed to a more segregated pattern at the level of the PN found by Brodal et al. (1991).

A possible explanation for such a complex pattern of overlap and nonoverlap of termination in the pontine nuclei emerges from studies investigating the granular layer of the cerebellar cortex - the major target of pontine projection neurons. As already pointed out in the introductory remarks, the granular layer 

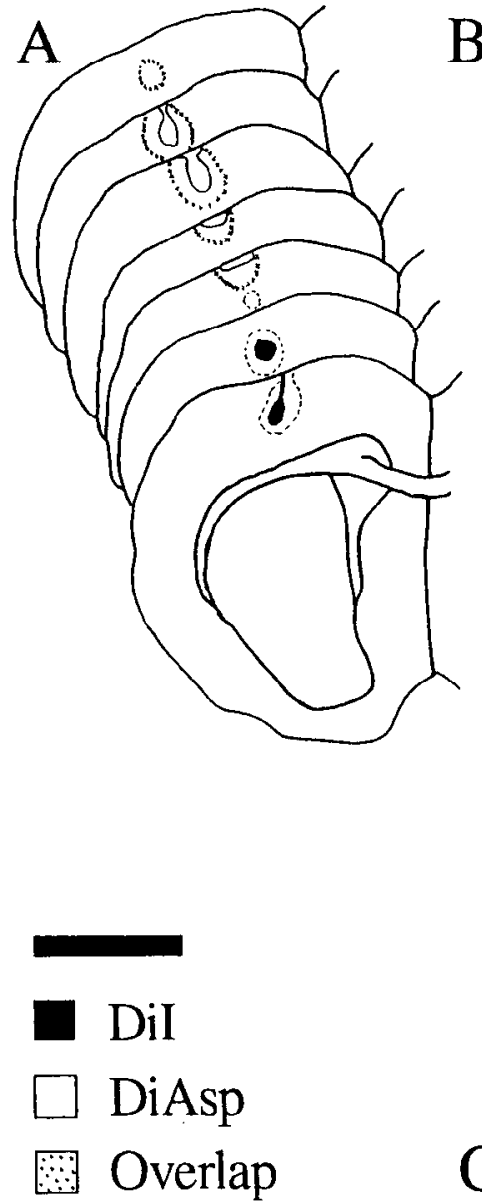

B
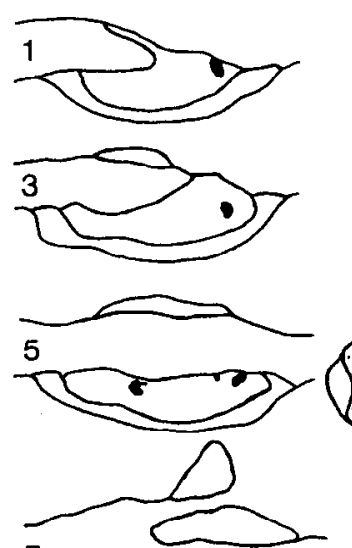

7
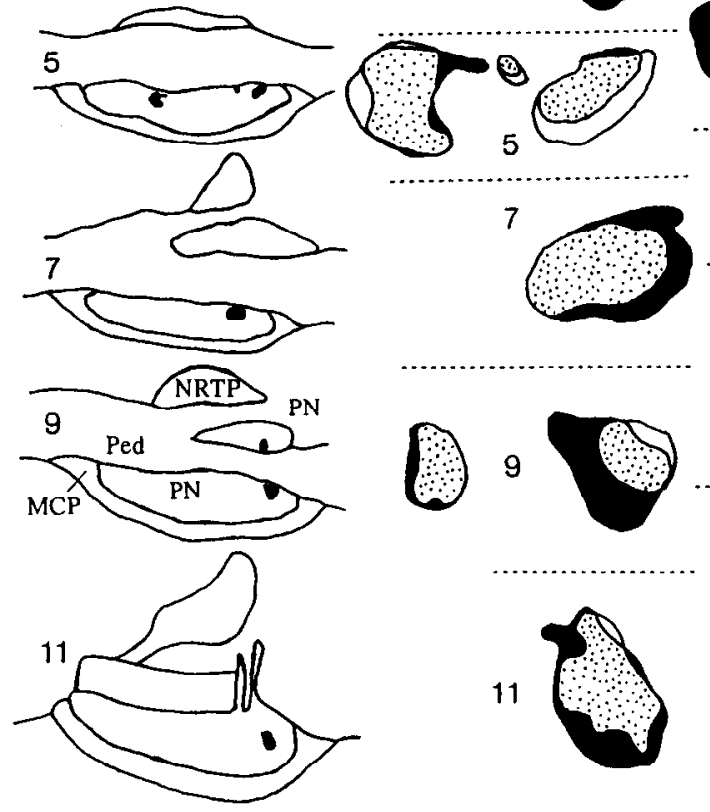

9
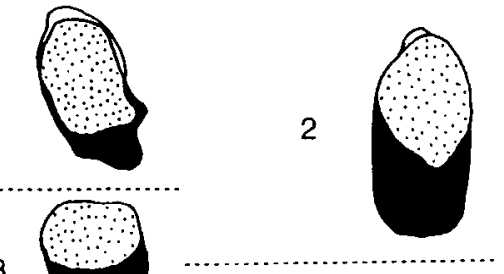

3
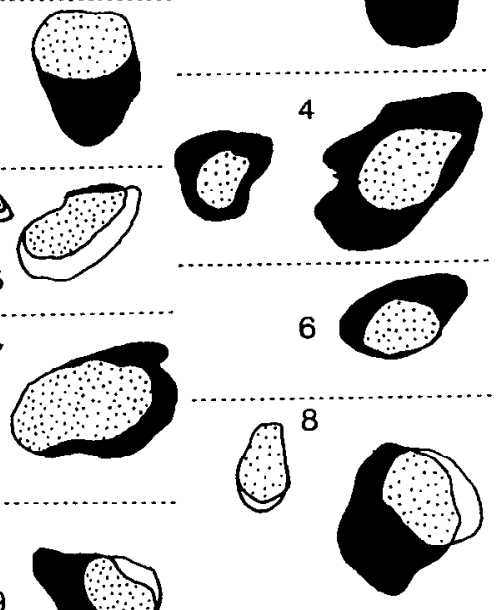

10<smiles>c1ccc2ccccc2c1</smiles>

11
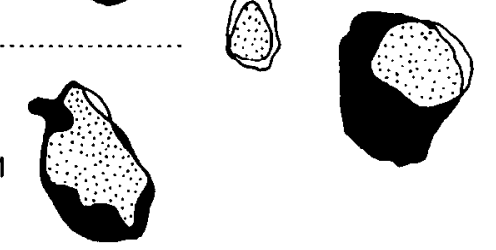
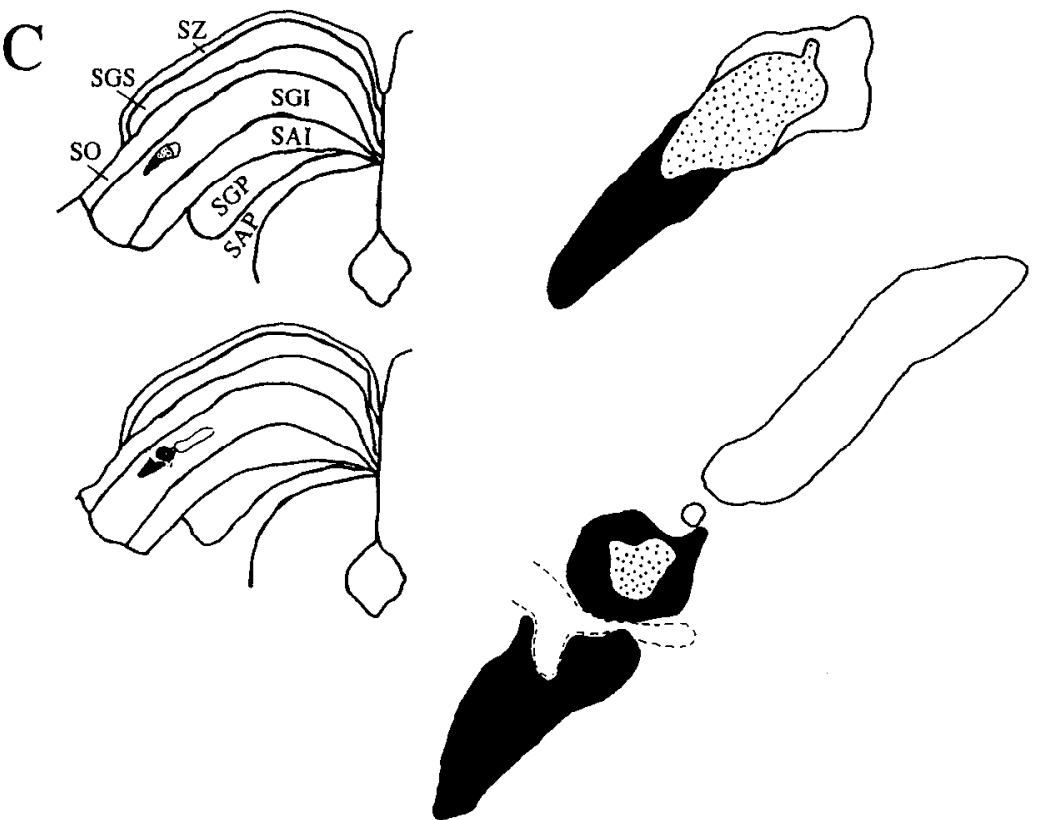

Figure 11. Drawing of the double anterograde label of the case shown in Figure 9, $E$ and $F$. A, Injection sites of DiI and DiAsp in SmI. The first section is at bregma 1.0. The sections are ordered from frontal to caudal (distance $200 \mu \mathrm{m}$ ). $B$, Label in parasagittal sections of the PN. On the right, the patches of Dil and DiAsp are shown (distance between sections $100 \mu \mathrm{m}$ ). On the left side, the localization of the label within the PN is shown in every second section. The terminal fields labeled by the two dyes overlap to a high degree. In the second and third section a small DiAsplabeled terminal field lies entirely within a larger one labeled with Dil. In the fifth section this is seen vice versa. The eighth to tenth sections show a certain shift of the two labeled terminal fields at a ventral pontine site, while a nearly total overlap of the two dyes was observed in the dorsal PN. C, Label in frontal sections of the SC (distance $200 \mu \mathrm{m}$ ). Terminal fields located in the lateral part of the SC in the SGI are shown. The enlarged drawing of the terminal fields demonstrates that they were well separated from each other and show a consistent shift with respect to each other. In the second section a patchy but nonetheless topographically arranged distribution of the two terminal fields is seen. Conventions and scale bars are as in Figure 10. 


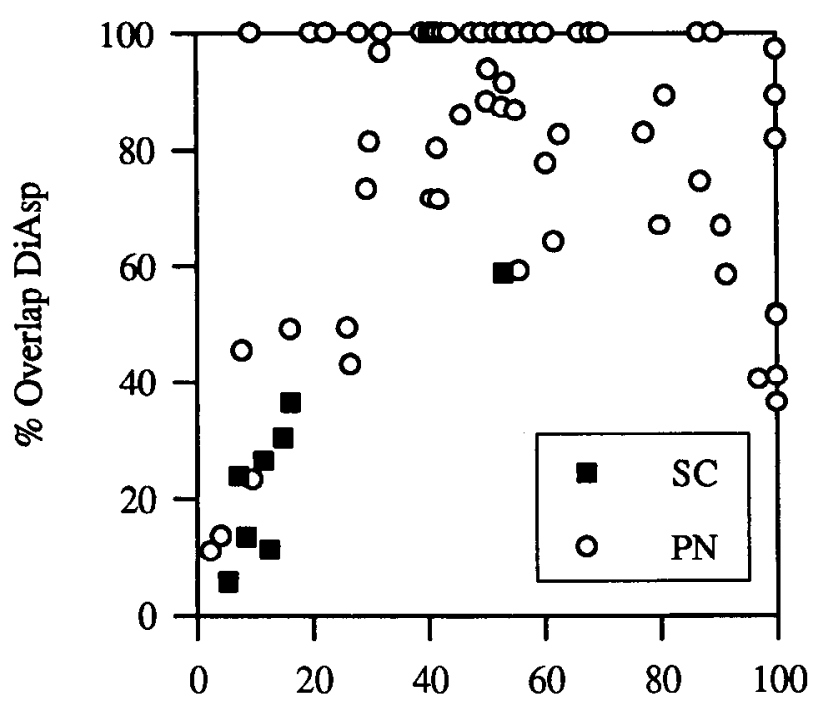

$\%$ Overlap Dil

Figure 12. Degree of overlap of terminal fields within SC and PN. The percentage of overlap of terminal fields labeled by one tracer with the terminal field labeled by the second one was measured. The measures for each dye were then plotted against each other for teminal fields found in the PN and $\mathrm{SC}$ in all cases examined. Compared with the percentage of overlap in the SC, the PN label displayed larger overlap zones. In most cases, the terminal fields in the $\mathrm{PN}$ are not congruent. As indicated by the data points along the $100 \%$ lines of each tracer, often a terminal field labeled by one tracer is included within that labeled by the other. Note a slight shift of the data points to the upper left part of the diagram, indicating a tendency to overestimate the percentage of overlap in terminal fields labeled with DiAsp (see Methodological considerations in the Discussion for more detail).

of the cerebellum is subdivided into patches such that neighboring patches typically receive somatosensory information from widely separated parts of the body (Joseph et al., 1978; Shambes et al., 1978a,b). Electrical stimulation of sites in SmI have shown that only somatotopically corresponding sites of the map in the granular layer are excited from SmI (Bower et al., 1981). Furthermore, the effects resulting from stimulation of one SmI site have been reported to be well confined to one patch in the granular layer in crus IIa (Bower et al., 1981). If, as the latter authors suggested, the cortical map is projected via the PN onto the one in the cerebellum, two organizational principles would be expected to be realized in the cerebropontocerebellar pathway. First, we would expect a loss of fine-grained topography in order to explain the large cerebellar receptive fields. Second, precise spatial connections would be required to account for the fragmentation of the cerebellar map. Our present findings of dendritic fields of projection neurons respecting borders of pontine compartments and the loss of topographical order in the corticopontine projection meet these requirements very well. Together with the long known patchy projection pattern, they may represent the morphological substrate of a fractured somatotopy already present on the level of the PN and handed over to the cerebellum. Complex overlapping and nonoverlapping patterns of terminal fields labeled from adjacent cortical locations as observed in the present study and by others (Brodal et al., 1991) would be expected if at least one of the injection sites was located on the border between cortical regions projecting to different compartments in the PN.

The studies describing the fragmentation of the cerebellar map in addition report that a certain degree of somatotopy may be preserved within patches in the granular layer (Joseph et al., 1978; Shambes et al., 1978a,b; Bower et al., 1981). However, this somatotopy could not be demonstrated within every patch those authors mapped. Even if present principally, the large sizes of receptive fields in the granular layer and the concomitant large overlap area of receptive fields within a given patch will reduce the resolution of the map significantly. Therefore, the somatotopy within a patch, if present, is coarse. Our occasional finding of a certain shift of terminal fields labeled with two different anterograde tracers (Fig. 11) together with our observation that some of the dendritic fields of pontine projection neurons were not dependent on the border of a neighboring terminal field (dots with positive difference in Fig. 8) may well account for the preserved somatotopy within some fragments in the cerebellar map.

While we suggest that the essential features of the cerebellar map may originate from the features of the corticopontine projection, there is no reason to exclude the possibility that the organization of the pontocerebellar projection may contribute to this transformation as well. Rather, the fact that the pontocerebellar projection also shows a patchy and divergent organization (Mihailoff et al., 1981b; Mihailoff, 1983; Nikundiwe et al., 1994) suggests that the transformation of the continuous cortical into the fractured cerebellar map might be established in two steps, including the corticopontine as well as the pontocerebellar projection.

\section{A parallel gate for multiple channels of cortical sensorimotor information? Speculations on the function of the PN}

Irrespective of the functional role of the fractured somatotopy in the cerebellum, we may ask what the possible advantage of the partition of the cerebrocerebellar pathway into two sections may be. It is suggestive that the PN may represent a stage allowing for modulation of cortical information hefore it enters the cerebellum. As single modules were found to be segregated in the PN in the present study, cortical information might not be influenced only as a whole. Rather, modules might be assessed independently from each other to influence individual channels of sensorimotor information. One possible source of influence of individual pontine modules may be the back projection from the cerebellar nuclei to the PN, which also is patchy in nature and partly includes inhibitory fibers (Watt and Mihailoff, 1983; Border et al., 1986; Lee and Mihailoff, 1990; Border and Mihailoff, 1991). In particular, corticopontine and cerebellopontine terminal fields were shown to overlap in the PN and fibers of both projection systems may even end on the same pontine neurons (Lee and Mihailoff, 1990). Other systems which show a patchy or clustered appearance and thus may possibly influence individual modules are pontine GABAergic neurons (rat: Border and Mihailoff, 1985; monkey: Thier and Koehler, 1987; rat, cat, and monkey: Brodal et al., 1988) or axon collaterals of corticopontine neurons (Mihailoff, 1978).

What might be the benefit of the possibility to selectively influence single pontine modules? One speculation is that such selective influence on individual pontine modules may be used to select those channels of sensorimotor information which are needed for the control of a given motor program and to block those which are irrelevant. The fractured map in the cerebellum assures that any location on the cerebellar cortex contains a distinct, spatially aligned subset of neocortical information. This presumably allows the cerebellar cortex to locally integrate dif- 
ferent kinds of sensory and motor information meeded for the control of a given movement. It follows that only those sites on the cerebellar map which represent the relevant subsets of information should be active at a time. However, sensorimotor information not needed to control a given movement may erroneously activate "false" cerebellar sites and therefore contribute to an increase of noise in the cerebellar output. Thus, filtering out these irrelevant cerebrocerebellar channels may be needed to improve the performance of the cerebellum. Taking the segregation of modules as shown in the present study and the patchiness of afferent projections into account, the PN appear well suited to achieve this task by selectively gating multiple sensorimotor channels of cerebral sensorimotor information.

\section{References}

Baker J, Gibson A, Glickstein M, Stein J (1976) Visual cells in the pontine nuclei of the cat. J Physiol (Lond) 255:415-433.

Bjaalie JG (1989) The corticopontine projection from area 20 and surrounding areas in the cat: terminal fields and distribution of cells of origin as compared to other visual cortical areas. Neuroscience 29:8193.

Bjaalie JG, Brodal P (1989) Visual pathways to the cerebellum: segregation in the pontine nuclei of terminal fields from different visual cortical areas in the cat. Neuroscience 29:95-107.

Border BG, Mihailoff GA (1985) GAD-immunoreactive neural elements in the basilar pontine nuclei and nucleus reticularis tegmenti pontis of the rat. I. Light microscopic studies. Exp Brain Res 59:600-614.

Border BG, Mihailoff GA (1991) Glutamate immunoreactivity in the rat basilar pons: light and electron microscopy reveals labeled boutons and cells of origin of afferent projection. Neuroscience 45:47-61.

Border BG, Kosinski RJ, Azizi SA, Mihailoff GA (1986) Certain basilar pontine afferent systems are GABA-ergic: combined HRP and immunocytochemical studies in the rat. Brain Res Bull 17:169-179.

Bower JM, Beermann DH, Gibson JM, Shambes GM, Welker W (1981) Principles of organization of a cerebro-cerebellar circuit. Brain Behav Evol 18:1-18.

Brodal P (1968a) The corticopontine projection in the cat. I. Demonstration of a somatotopically organized projection from the primary sensorimotor cortex. Exp Brain Res 5:210-234.

Brodal P (1968b) The corticopontine projection in the cat. Demonstration of a somatotopically organized projection from the second somatosensory cortex. Arch Ital Biol 106:310-322.

Brodal P (1978) The corticopontine projection in the rhesus monkey. Origin and principles of organization. Brain 101:251-283.

Brodal P (1987) Organization of cerebropontocerebellar connections as studied with anterograde and retrograde transport of HRP-WGA in the cat. In: New concepts in cerebellar neurobiology, pp 151-182. New York: Liss.

Brodal P, Bjaalie JG (1992) Organization of the pontine nuclei. Neurosci Res 13:83-118.

Brodal P, Mihailoff GA, Border BG, Ottersen OP, Storm-Mathisen J (1988) GABA-containing neurons in the pontine nuclei of the rat, cat and monkey. An immunocytochemical study. Neuroscience 25:27-45.

Brodal P, Bjaalie JG, Aas J-E (1991) Organization of cingulo-pontocerebellar in the cat. Anat Embryol 184:245-254.

Burne RA, Mihailoff GA, Woodward DJ (1978) Visual corticopontine input to the paraflocculus: a combined autoradiographic and horseradish peroxidase study. Brain Res 143:139-146.

Dräger UC, Hubcl DH (1976) Topography of visual and somatosensory projections to mouse superior colliculus. J Neurophysiol 39:91-101.

Harvey AR, Worthington DR (1990) The projection from different visual cortical areas to the rat superior colliculus. J Comp Neurol 208:281292.

Huerta MF, Harting JK (1984) The mammalian superior colliculus: studies of its morphology and connections. In: Comparative neurology of the optic tectum (Vanegas H, ed), pp 687-773. New York: Plenum.

Joseph JW, Shambes GM, Gibson JM, Welker W (1978) Tactile projections to granule cells in caudal vermis of the rat's cerebellum. Brain Behav Evol 15:141-149.

Lee HS, Mihailoff GA (1990) Convergence of cortical and cerebellar projections on single basilar pontine neurons: a light and electron microscopic study in the rat. Neuroscience 39:561-577.
Loew LM, Simpson LL (1981) Charge shift probes of membrane potential. A probable electrochromic mechanism for $p$-aminostyrylpyridinium probes on a hemispherical lipid bilayer. Biophys $\mathbf{J}$ 34:353.

Mihailoff GA (1978) Principal neurons of the basilar pons as the source of a recurrent collateral system. Brain Res Bull 3:319-332.

Mihailoff GA (1983) Intra- and interhemispheric collateral branching in the rat pontocerebellar system, a fluorescence double-label study. Neuroscience 10:141-160.

Mihailoff GA, McArdle CB (1981) The cytoarchitecture, cytology, and synaptic organization of the basilar pontine nuclei in the rat. II. Electron microscopic studies. J Comp Neurol 195:203-219.

Mihailoff GA, Burne RA, Woodward DJ (1978) Projections of the sensorimotor cortex to the basilar pontine nuclei in the rat: an autoradiographic study. Brain Res 145:347-354.

Mihailoff GA, McArdle CB, Adams CE (1981a) The cytoarchitecture, cytology, and synaptic organization of the basilar pontine nuclei in the rat. I. Nissl and golgi studies. J Comp Neurol 195:181-201.

Miluilorf GA, Burne RA, Azizi SA, Norell G, Woodward DJ (1981b) The pontocerebellar system in the rat: an HRP study. II. Hemispheral components. J Comp Neurol 197:559 -577.

Mihailoff GA, Adams CE, Woodward DJ (1984) An autoradiographic study of the postnatal development of sensorimotor and visual components of the corticopontine system. J Comp Neurol 222:1 16-127.

Mihailoff GA, Lee H, Watt CB, Yates R (1985) Projections to the basilar pontine nuclei from face sensory and motor regions of the cerebral cortex in the rat. J Comp Neurol 237:251-263.

Nikundiwe AM, Bjaalie JG, Brodal P (1994) Lamellar organization of pontocerebellar neuronal populations. A multi-tracer and 3-D computer reconstruction study in the cat. Eur J Neurosci 6:173-186.

Oka H, Sasaki K, Matsuda Y, Yasuda T, Mizuno N (1975) Responses of pontocerebellar neurones to stimulation of the parietal association and the frontal motor cortices. Brain Res 93:399-407.

O'Leary DDM, Koester SE (1993) Development of projection neuron types, axon pathways, and patterned connections of the mammalian cortex. Neuron 10:991-1006.

Paxinos G, Watson C (1986) The rat brain in stereotaxic coordinates. San Diego: Academic/Harcourt Brace Jovanovich.

Potter RF, Rüegg DG, Wiesendanger M (1978) Responses of neurones of the pontine nuclei to stimulation of the sensorimotor, visual and auditory cortex of rats. Brain Res Bull 3:15-19.

Rüegg D, Wiesendanger M (1975) Cortigofugal effects from sensorimotor area I and somatosensory area II on neurons of the pontine nuclei in the cat. J Physiol (Lond) 247:745-757.

Rüegg D, Séguin JJ, Wiesendanger M (1977) Effects of electrical stimulation of somatosensory and motor areas of the cerebral cortex on neurons of the pontine nuclei in squirrel monkeys. Neuroscience 2:923-927.

Sefton J, Dreher B (1985) Visual system. In: The rat nervous system (Paxinos G, ed), pp 169-221. Sydney: Academic.

Shambes GM, Beermann DH, Welker WI (1978a) Multiple tactile areas in cerebellar cortex: another patchy cutaneous projection to granule cell columns in the rat. Brain Res 156:123-128.

Shambes GM, Gibson JM, Welker WI (1978b) Fractured somatotopy in granule cell tactile areas of rat cerebellar hemispheres revealed by micromapping. Brain Behav Evol 15:94-140.

Stein BE, Magalhaes-Castro B, Kruger L (1976) Relationship between visual and tactile representations in cat superior colliculus. J Neurophysiol 39:401-419.

Suzuki DA, May JG, Keller EL, Yee RD (1990) Visual motion response properties of neurons in dorsolateral pontine nucleus of alert monkey. J Neurophysiol 63:37-59.

Thier P, Koehler W (1987) Morphology, number and distribution of putative GABA-ergic neurons in the basilar pontine gray of the monkey. J Comp Neurol 265:311-322.

Thier P, Koehler W, Buettner UW (1988) Neuronal activity in the dorsolateral pontine nucleus of the alert monkey modulated by visual stimuli and eye movements. Exp Brain Res 70:496-512.

Watt CB, Mihailoff GA (1983) The cerebellopontine system in the rat. I. Autoradiographic studies. J Comp Neurol 215:312-330.

Wiesendanger R, Wiesendanger $M$ (1982) The corticopontine system in the rat. II. The projection pattern. J Comp Neurol 208:227-238.

Wise SP, Jones EG (1977) Cells of origin and terminal distribution of descending projections of the rat somatosensory system. J Comp Neurol 175:129-158.

Yeomans JS (1990) Principles of brain stimulation. New York: Oxford UP. 